\title{
Study of the compression behaviour of grape seeds using the Finite Element Method
}

\author{
Carmen Vasilachi (Baltățu) ${ }^{1 *}$, Sorin-Ștefan Biriș ${ }^{2}$ and Gabriel Gheorghe ${ }^{1}$ \\ ${ }^{1}$ National Institute of Research - Development for Machines and Installations Designed to Agriculture \\ and Food Industry - INMA, Bucharest, Romania \\ ${ }^{2}$ University Politehnica Bucharest, Faculty of Biotechnical Systems Engineering, Romania
}

\begin{abstract}
It is important to know all phenomena that occur during compression of grape seeds because are very complex. Studying these phenomena can help us in increasing the performance of the equipment. Also for the pressing of oilseed materials, it is helpful to understand the compression behavior of grape seeds. The purpose of this study is to find how the stress and deformation propagate in grape seeds during the compression process. Therefore, we used an advanced engineering method named finite element method that shows the propagations of stress and strain fields in grape seeds. In this paper, we made a two dimensional model of grape seed and we analyzing the dispersion of stress and strain with a dedicated software FEM. In the end, to validate the FEM model we made a compression test on grape seeds using a Hounsfield unit. This study is for highlighting the importance of the orientation of the grape seeds during the pressing process to reduce the energy consumed.
\end{abstract}

\section{Introduction}

Nowadays, it is very important to use alternative resources, as conventional resources are increasingly limited. That is why, in recent years, there has been a developing interest in obtaining oil from oilseeds and oil plants. Researchers have shown that these oils have nutritional elements useful for human body health and have other necessary properties which can be used in other industrial areas, for which the current technology rewards us for obtaining these resources, [1]. This category also includes grape seed oil that is obtained from grape seeds resulting from the processing of grapes in winemaking industries.

If we consider that grape seeds are a new material, it is important to know their mechanical, physical properties and behavior during pressing. At the same time, stress and strain modeling is very important because it allows us to establish a technological line for their processing and we can estimate the energy consumption needed to obtain the oil. This modeling is done with the help of the programs using the finite element method and for this we must eliminate the physical and mechanical characteristics, respectively Young's modulus and Poisson's coefficient, [2].

\footnotetext{
* Corresponding author: carmen.vasilachi@gmail.com
} 
For a clearer picture of the physical properties of grape seeds, Avshalom Karasik and co-workers made a 3D scan two types of seeds from Hadari and Merlot grapes, as in Fig.1, where it can be noticed at point c) that the width of the seed has a slight variation of from one variety to another, [3].

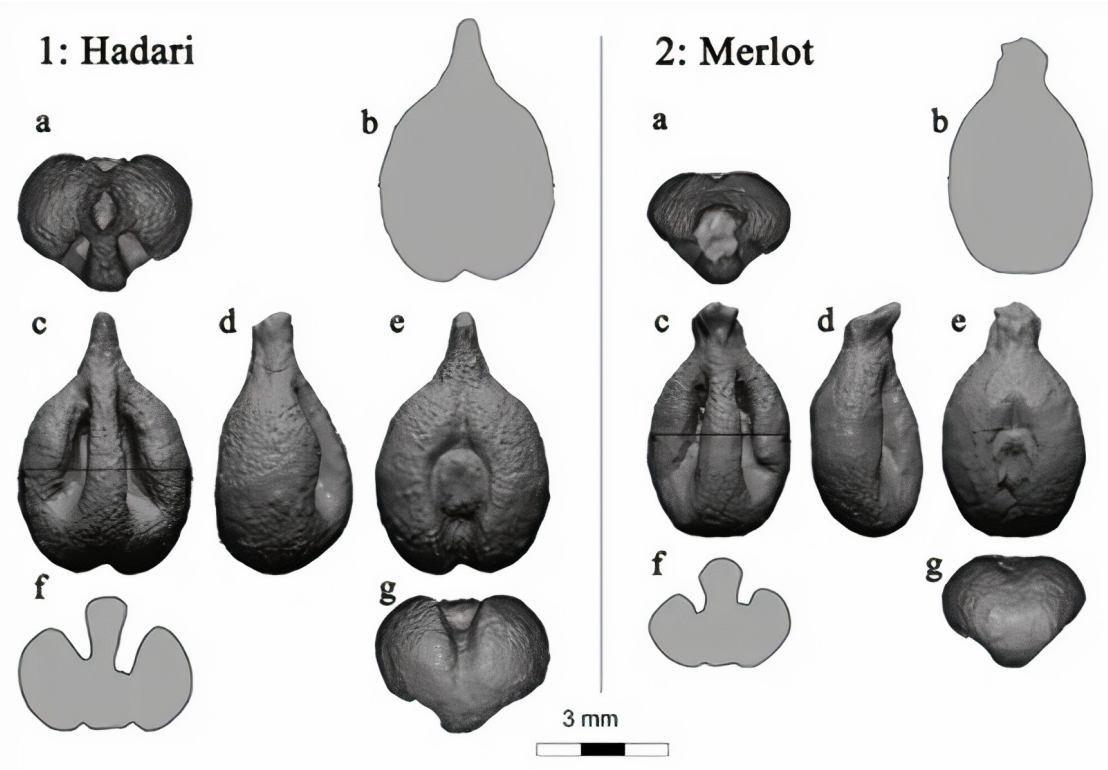

Fig. 1. 3D scan of grape seed views (a, c, d, e, g) and across- sections (b, f) from two varieties 1: Hadari (indigenous Israeli variety), 2: Merlot (international variety) [3]

In specialized literature, the physical and mechanical properties of grape seeds make subject for just small studies, these still being a topic in the early stages of development. However, L. ROLLE in his research has come to the conclusion that Young's module evolution of seeds a few weeks after harvesting the grapes tends to grow with the drying process. This is explained by the fact that Young's module is dependent on the size of the seeds, therefore it may have a variation from one seed to another or from one period to another, [4]. In this article we measured and calculated the physical and mechanical properties of grape seeds and Burgung variety.

At the same time, in specialized literature, it was concluded that the positioning of the seed at the time of compression, either vertically or horizontally, is important. In the upright position the sampler absorbs more energy to be broken than in the horizontal position. This article aims to highlight the propagation of deformations and forces inside the grape seeds during compression.

\section{Material and Methods}

For this paper, Burgund grape seeds were used to represent the physical and mechanical properties. The grape marc was obtained from the research station INCDBH Stefanesti harvest from October 2019. To get the seeds from grape marc, it was necessary to dry the mixture of tails, seeds, and skin, after that we separated the seeds from the rest of all. In finaly we obtain the grape seeds as in Fig.2. 


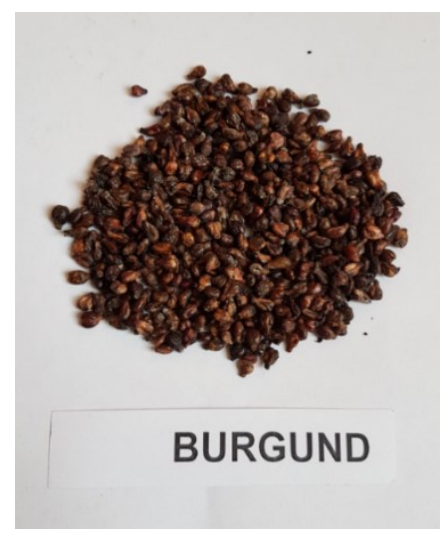

Fig. 2. Grape seeds of the Burgund type

The physical properties of the seeds can be observed in Table 1 and were determined as follows: the dimensions on the three axes were obtained using a digital caliper (x- length axis, y-width axis, z-thickness axis) and also the seeds were weighed to determine the unit mass but also the mass of 100 seeds.

Table 1 The physical properties of grape seeds

\begin{tabular}{|c|c|c|c|c|c|c|c|}
\hline \multirow{2}{*}{ No. } & \multirow{2}{*}{$\begin{array}{c}\text { Variety } \\
\text { Name }\end{array}$} & \multicolumn{6}{|c|}{ Caracteristici geometrice de baza } \\
\cline { 3 - 5 } & $\begin{array}{c}\mathbf{x}- \\
\text { length }\end{array}$ & $\begin{array}{c}\mathbf{y}- \\
\text { width }\end{array}$ & $\begin{array}{c}\mathbf{z}- \\
\mathbf{d e p t h}\end{array}$ & $\begin{array}{c}\text { Unit mass } \\
\text { [g] }\end{array}$ & $\begin{array}{c}\text { Mass } \\
\text { for 100 } \\
\text { of seeds } \\
{[\mathbf{g}]}\end{array}$ & $\begin{array}{c}\text { Umiditate } \\
{[\%]}\end{array}$ \\
\hline 1 & Burgund & 6.00 & 3.92 & 2.61 & 0.027 & 33.45 & 4.7 \\
\hline
\end{tabular}

We determined the mechanical properties of grape seeds using a uniaxial compression equipment, Fig.3. After the proper test, a force-displacement curve is obtained for uniaxial compression, [5]. With the help of the obtained data imported information resulted about the hardness of the seeds, the apparent modulus of elasticity, the energy consumed for breaking, drilling and moving at different times, etc.

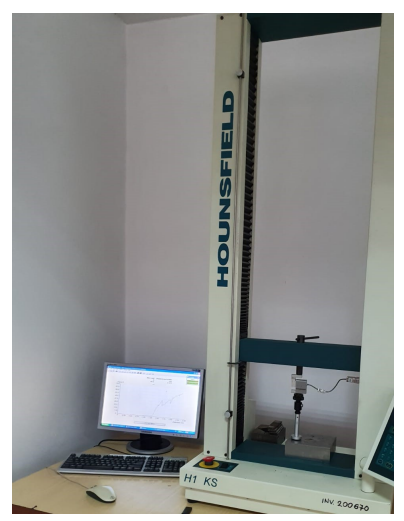

Fig. 3. Hounsfield / Tinius Olsen mechanical test unit, model H1 KS 
The grape seeds were placed between the fixed plate and the mobile plate with a speed of $1 \mathrm{~mm} / \mathrm{min}$, of Hounsfield equipment. Strength and stress were recorded and saved using the software dedicated to the machine. After performing the compression test, a forcedisplacement graphic was shown, Fig. 4.

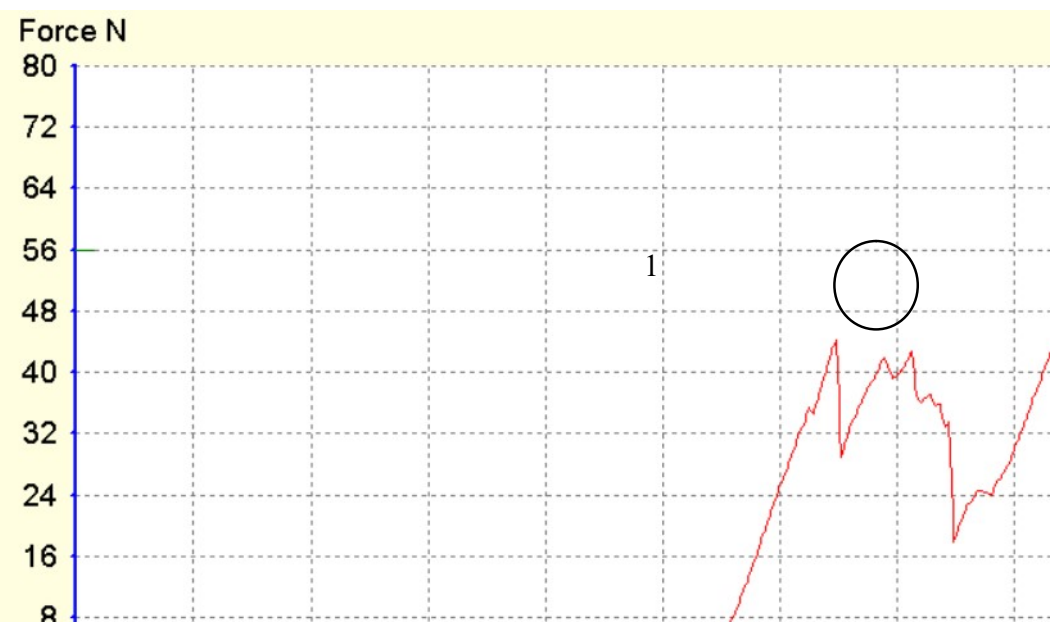

Fig. 4. Force-Extension graph for Burgund grape seeds

In the point marked with "1" on the force-displacement graph, the grape seed is broken off and appears an immediate force breakage. The maximum force applied to this seed was $56 \mathrm{~N}$ and it was sufficient to break the seed, [6] .

The obtained results are used to create a mesh model, as in Fig. 5, which is necessary for FEM modeling of propagation of deformation stress in grape seeds. For modeling, we used a software called QuickField Elements Analysis System which created a graphic displacement for let us know what happened in the interior of the grape seeds.

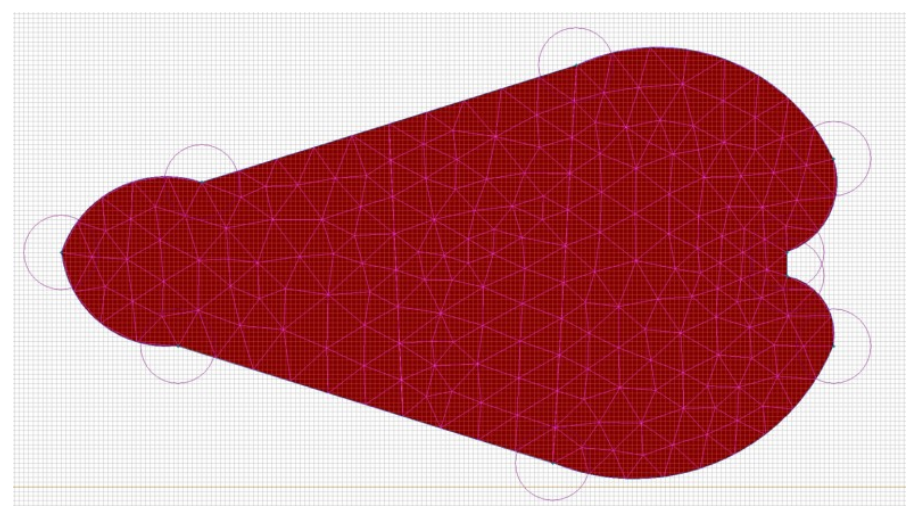

Fig. 5. Mashed model of a grape seeds

The characteristics of the material needed in seed modeling were compared with those of the specialized literature and introduced in software, such as Young's module has the value $22 \mathrm{MPa}$ [5], respectively Poisson's ratio was 0.36 [6]. 


\section{Results and discussion}

The 2D drawing of the grape seed was made and the knots for the mash were made in the QuickField program, we introduced the material characteristics and applied the force on the horizontal side of the seed. As a result, we obtained the distribution of equivalent stress, Fig. 6 and all the displacements within the seed, Fig.7.
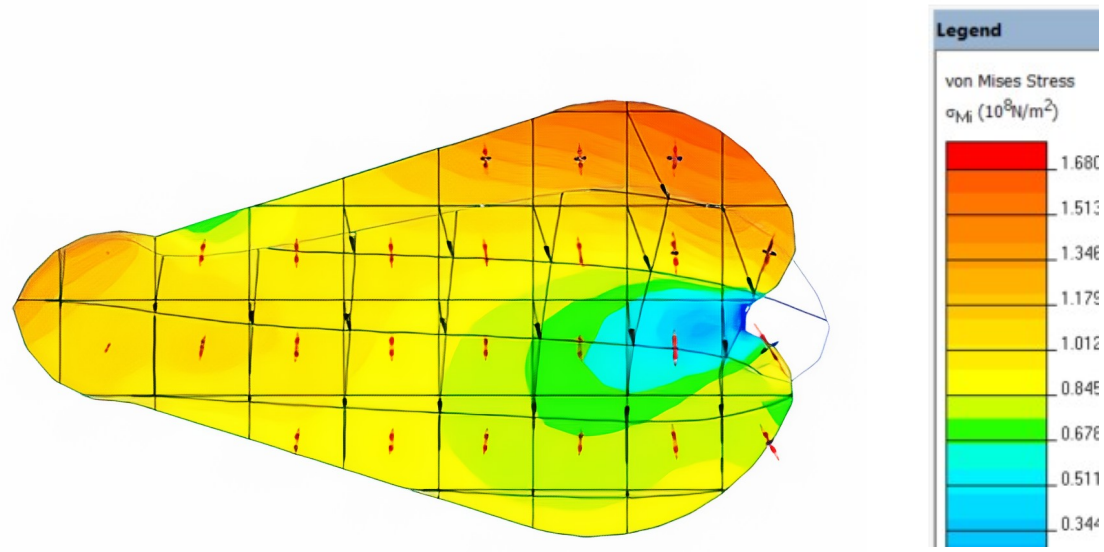

Fig. 6. Distribution of equivalent stress in the grape seeds

In Fig. 6 can be noticed that the highest stress is found in the contact area between seeds and the plate of the test equipment. It can be observed that the highest force is about $168 \mathrm{MPa}$.

In Fig. 7, can be observed the distribution of displacements and how the grape seeds are deformed during the compression process. The largest displacements are found in the contact area between the moving plate and the seed, the displacements have a vertical direction.

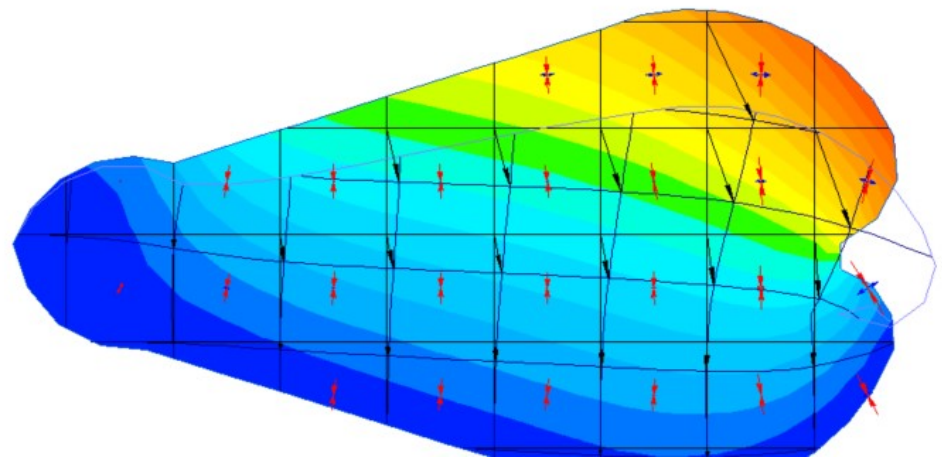

Fig. 7. Distribution of equivalent displacement in the grape seeds 
In Fig. 8, the grape seed was placed upright and it is observed that the force is applied at the top of the seed. It is also noted that the contact area between the seeds and the mobile plate is smaller. The force required to compress the seed must be greater, we can conclude that in a vertical position the energy consumption of the higher seed.

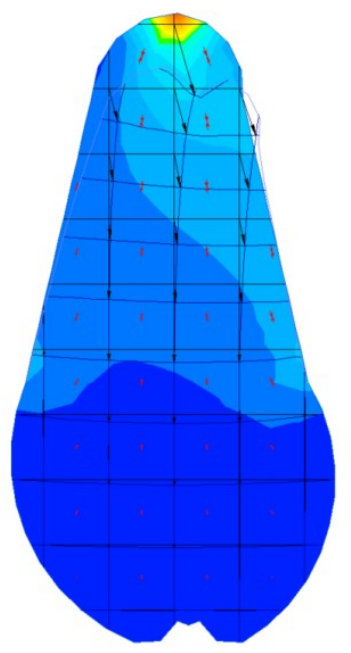

a.
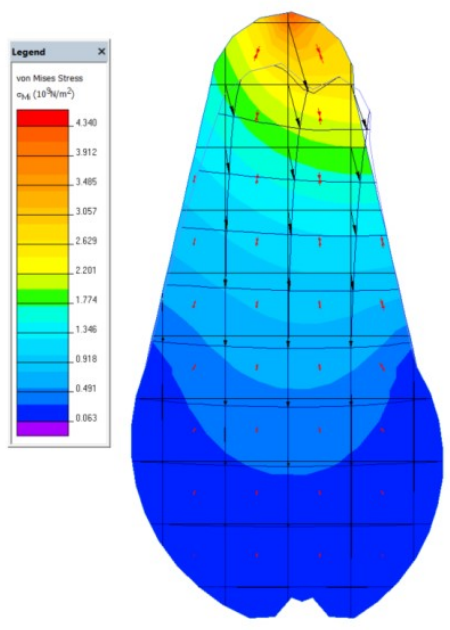

b.

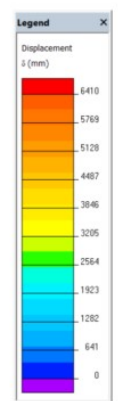

Fig. 8. Distribution of equivalent stress(a) and displacements (b) in the grape seeds oriented vertycally

The QuickField program also created a graph of stress distribution during the simulation of compression with the force indicated by us in the system for the both positions. In Fig. 8 and Fig.9, we observe the stress - extension curve for bouth positions which has a peak of resistance after which the force has a sharp decrease which means that that is the point where the seed has broken. This graph is approximately similar to the one in Fig. 4. Different from the two graphs is that in the case of the vertical position a greater force was needed to break the grape seed.

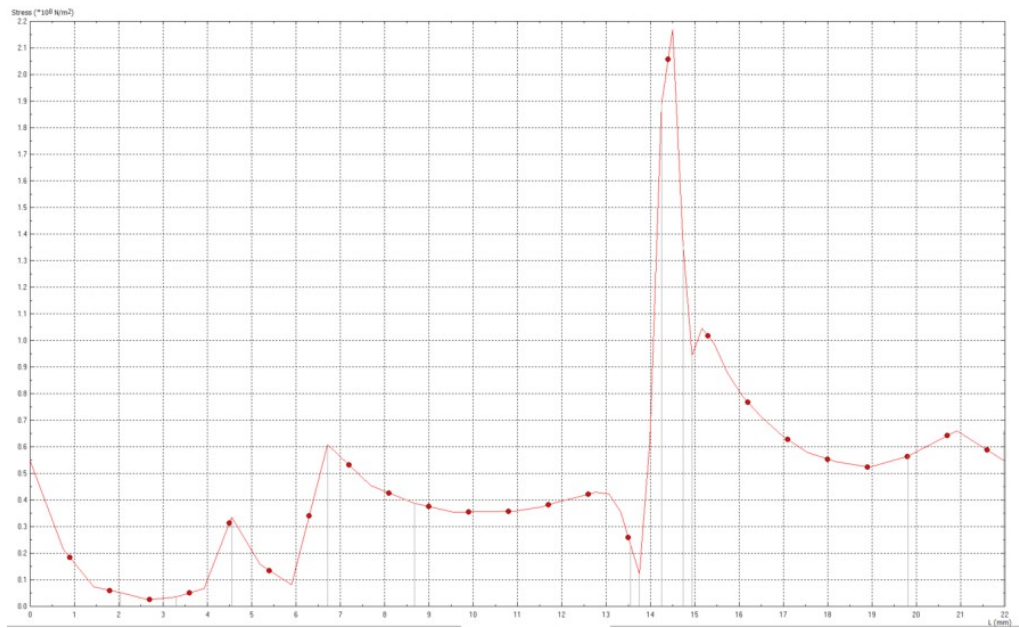

Fig. 9. Force-Extesnion graph from QuickFild when the grape seed is oriented horizontal 


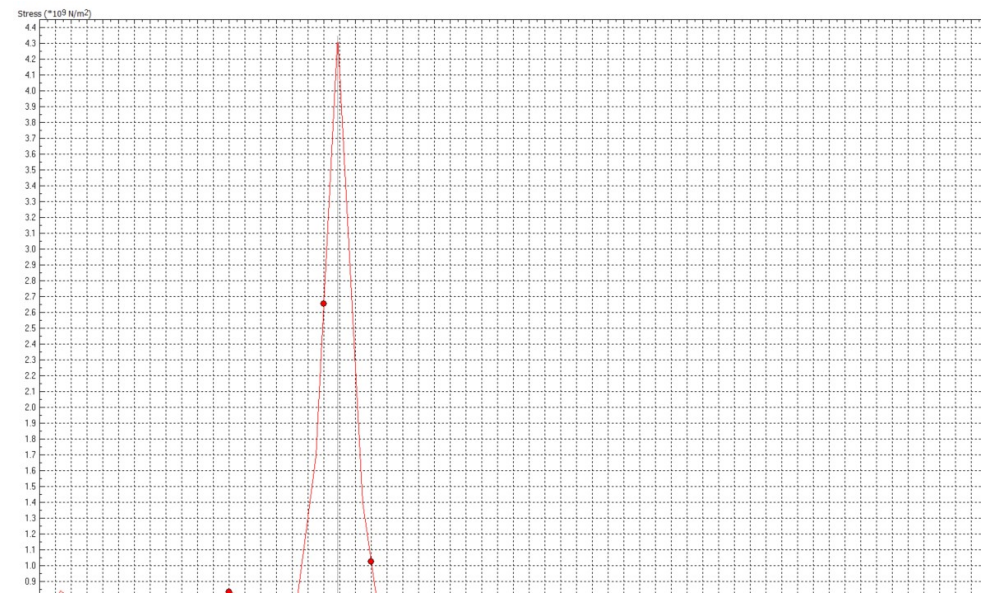

Fig. 10. Force-Extesnion graph from QuickFild when the grape seed is oriented vertically

\section{Conclusions}

The Finite Element Method is the advanced engineering tool for processing numerical and mathematical modeling and it was very helping in this work to demonstrate the importance of grape seeds position during the compression time.

In conclusion, it is more advantageous to positioned horizontally the grape seed during the compression test because the contact area is larger than in the vertical orientation. The displacement distribution is more constant and on a larger surface in the interior of seeds in a horizontal position. In order to optimize the pressing process by reducing the energy consumption used, a technical solution for directing the grape seeds can be found so that the horizontal parts to be in contact with the pressing screw.

This work has been funded by the European Social Fund from the Sectoral Operational Programme Human Capital 2014-2020, through the Financial Agreement with the title "Scholarships for entrepreneurial education among doctoral students and postdoctoral researchers (Be Antreprenor!)", Contract no. 51680/09.07.2019 - SMIS code: 124539.

This work was supported by the Romanian Education and Research Ministry, through through Programme 1 - Development of the national research-development system, subprogramme 1.2 - Institutional performance - Projects for financing excellence in RDI, contract no. 16PFE.

\section{References}

[1] D. J. Epasinghe, C. K.Y. Yiu, M. F. Burrow, Mechanical properties, water sorption characteristics, and compound release of grape seed extract-incorporated resins, JAOS Journal of Applied Oral Science, vol. 25 no.4 Bauru July/Aug. (2017)

[2] R.K. Gupta, S.K. Das, Fracture resistance of sun ower seed and kernel to compressive loading, Journal of Food Engineering, 46 (2000)

[3] A. Karasik, O. Rahimi, M. David, E. Weiss, E. Drori, Development of a $3 D$ seed morphological tool for grapevine variety identifcation, and its comparison with SSR analysis, SCIENTIFC REPORTS , 8 (2018), DOI:10.1038/s41598-018-24738-9

[4] L.Rolle, F. Torchio , B.Lorrain, S. Giacosa, S. Río Segade, E. Cagnasso, V. GERBI, P.L. Teissedre, Rapid methods for the evaluation of total phenol content and extractability 
in intact grape seeds of cabernet-sauvignon: instrumental mechanical properties and FTNIR spectrum, J. Int. Sci. Vigne Vin, 46 (2012)

[5] C. B. Vasilachi, S. S. Biris, G. Ipate, G. Gheorghe, Determination of the longitudinal modulus of elasticity for the different type of grape seeds, Conference Engineering for Rural Development, (2020), Jelgava.

[6] S. S. Biris, M. Ionescu, N.E. Gheorghita, N. Ungureanu, N.V. Vladut, Study of the compresion behavior of sunflower seeds using the Finite Element Method, AGROFORM International Journal, vol.4 (2019) 